\title{
Arcabouço conceitual do letramento informacional
}

\section{Kelley Cristine Gonçalves Dias Gasque}

Doutora e mestre em ciência da informação pela Universidade de Brasília, especialista em literatura brasileira pela Universidade Católica de Brasília. Professora adjunta da Universidade de Brasília, UnB - Brasília, DF, Brasil E-mail: kelleycristinegasque@hotmail.com

\section{Resumo}

Discute os conceitos relacionados ao letramento informacional, visando a propiciar um arcabouço conceitual mais objetivo e rigoroso mediante o desenvolvimento das representações mentais que integram esse processo, bem como as consequentes relações intrínsecas aos diversos sistemas conceituais com ele identificados. Tal empreendimento é importante para se pensar a partir do mesmo referencial de ideias. É proposta uma concepção de 'letramento informacional' com ênfase na aprendizagem, como processo de construção do conhecimento que pode contribuir para a sustentabilidade da vida e a solidariedade humana na sociedade contemporânea.

\section{Palavras-chave}

Letramento informacional. Alfabetização informacional. Competência informacional. Habilidades informacionais. Terminologia.

\section{Conceptual framework of information literacy}

\begin{abstract}
This article presents the concepts used in the scope of information literacy, providing a more rigorous and objective framework by means of the development of a structure of mental representations that integrates this process, as well as the resulting intrinsic links to other related concept systems. Such an undertaking is important in order to become possible to think considering the same referential basis of ideas. A conception of 'information literacy' is proposed, with emphasis on learning as a knowledge acquisition process that could therefore contribute to the sustainability of life and the human solidarity in contemporary society.
\end{abstract}

\section{Keywords}

Information literacy. Information . Information competency. Information ability. Terminology.

Ci. Inf., Brasília, DF, v. 39 n. 3, p.83-92, set./dez., 2010

\section{INTRODUÇÃO}

O letramento informacional constitui um processo que integra as ações de localizar, selecionar, acessar, organizar, usar informação e gerar conhecimento, visando à tomada de decisão e à resolução de problemas. Esse emergente tópico de pesquisa surge nos EUA na década de 70 , quando se cunha a expressão Information Literacy. Os estudos sobre o assunto intensificaram-se principalmente a partir das duas últimas décadas, chegando ao território brasileiro no início deste século.

Muitos são os termos e as expressões utilizados para traduzir o termo original - Information Literacy. $\mathrm{Na}$ Espanha, por exemplo, usa-se frequentemente 'Alfabetização Informacional' - ALFIN - (MARZAL; PRADO, 2007; TIRADO, 2010) e, em Portugal, 'Literacia da Informação'(SILVA; MARCIAL; MARTINS, 2007; TIRADO, 2010). No Brasil, foram publicados vários artigos e pesquisas, a partir de 2000, que utilizaram expressões como 'Information Literacy', letramento informacional', 'alfabetização informacional', 'habilidade informacional' e 'competência informacional' para se referir, em geral, à mesma ideia ou grupo de ideias. De acordo com Campello (2003), o termo Information Literacy foi mencionado, primeiramente, por Caregnato (2000), que o traduziu como 'alfabetização informacional', mas optou pelo emprego de 'habilidades informacionais' como seu equivalente em língua portuguesa. Apesar de constarem na literatura brasileira os conceitos supracitados, Information Literacy tem sido traduzido no Brasil comumente como 'competência informacional', conforme se observa nos trabalhos de Campello (2002), Miranda (2004), Belluzzo (2005), Silva et al (2005), Lins \& leite (2008), Vitorino (2008), Liston \& Santos (2009), Vitorino \& Piantola (2009), dentre outros. 
Embora esses conceitos ${ }^{1}$ estejam relacionados entre si, não devem ser empregados como sinônimos, na medida em que representam ações, eventos e ideias distintos. Essa limitação terminológica reflete a natureza emergente do tema, o que implica uma definição mais precisa dos conceitos relacionados à questão em causa para que seja possível a utilização do mesmo referencial de representação.

Ao reconhecer que as teorias subjacentes às práticas originam concepções distintas, o presente artigo trata dos conceitos utilizados no âmbito do letramento informacional com ênfase no aprendizado ao longo da vida. Pretende-se desenvolver um arcabouço conceitual mais objetivo e rigoroso mediante a estruturação das representações mentais que integram o processo e as consequentes relações intrínsecas aos diversos sistemas conceituais com ele identificados. Isso porque a significação constitui importante aspecto dos estudos por vincular-se aos significados estabelecidos e reconhecidos como certos e garantidos, que "nos habilitam a generalizar, a estender e a levar a nossa compreensão de uma coisa a outra" (DEWEY, 1979, p. 152).

O trabalho centra-se na reflexão sobre a terminologia do letramento informacional frequentemente utilizada no Brasil, qual seja, 'competências', 'habilidades', 'alfabetização', 'literacia' e 'letramento', e as relações estabelecidas entre os conceitos do mencionado processo.

\section{LITERACIA, LETRAMENTO OU ALFABETIZAÇÃO INFORMACIONAL?}

A despeito de reconhecer que os termos 'competências', 'habilidades', 'letramento', 'literacia' e 'alfabetização' pertencem a categorias de ideias similares, precisam ser bem definidos para que reflitam com exatidão determinada ação, evento ou processo. Ao analisá-los, constata-se uma relação mais estreita entre 'literacia', 'letramento' e 'alfabetização', assim como 'competência' e 'habilidades' estão vinculadas mais diretamente.

\footnotetext{
${ }^{1} \mathrm{O}$ conceito corresponde ao descritor de ideias, gerais ou abstratas, ao qual se vinculam diversas características que, por sua vez, conectam-se a outras representações (STERNBERG, 2000).
}

Desde a década de 70, a expressão 'Information Literacy' tem apresentado diferentes concepções de acordo com a ênfase e o contexto em que se insere, quais sejam, ênfase na tecnologia da informação (concepção da informação), ênfase nos processos cognitivos (concepção cognitiva) e ênfase no aprendizado (concepção da inteligência) (DUDZIAK, 2003).

De acordo com Dudziak (2003), a ênfase na tecnologia centra-se em uma abordagem voltada aos sistemas de informação, em que a aprendizagem ocorre de forma mecânica e se limita à aquisição de habilidades e conhecimentos instrumentais. Tal abordagem predominou nas décadas de 70 e $80 \mathrm{com}$ os estudos de Zurkowski (1974), Taylor (1979) e Garfield, (1979). A ênfase nos processos cognitivos emergiu em meados da década de 80 , em especial com os estudos de Breivik (1985) e Kuhlthau (1987). Nessa abordagem, o letramento informacional é compreendido como processo de busca de informação para a aquisição do conhecimento. Ao final da década de 90, começou-se a enfatizar a aprendizagem, considerando a dimensão social e ecológica do indivíduo. Bruce (1997) é uma das pesquisadoras que representa essa abordagem.

Um conceito bastante difundido e aceito por vários estudiosos da área foi proposto pela Association of College and Research Library (2000), em que Information Literacy refere-se a um conjunto de habilidades individuais que possibilitam ao sujeito reconhecer a informação necessária, bem como localizar, avaliar e utilizar eficazmente essa informação. A tradução do conceito em língua portuguesa seria 'literacia', como usado em alguns trabalhos lusitanos. No entanto, ele não consta nos principais dicionários de língua portuguesa do Brasil, como, por exemplo, Caldas Aulette (2009), Houaiss (199-?) ou o Moderno Dicionário de Lingua Portuguesa Michaelis (c1998).

Talvez por isso, Dudziak (2003) e Fialho (2009) preferiram usar 'Information Literacy' no original, em língua inglesa, apesar de mais adiante, optarem, respectivamente, pelas expressões 'competência

Ci. Inf., Brasília, DF, v. 39 n. 3, p.83-92, set./dez., 2010 
informacional' e 'letramento informacional'. O conceito usado no Brasil mais próximo da derivação do inglês literacy é ' letramento', de uso relativamente recente no campo da pedagogia e da educação (CALDAS AULETTE, 2009). No Brasil, alguns autores como Gasque (2006, 2008), Neves (2008) e, Campello (2009), em seu livro mais recente, optaram por esse termo.

Antes de abordar especificamente o contexto informacional, é necessário analisar mais detidamente o conceito de 'letramento', bastante utilizado no campo da educação. Ele emergiu no início da década de 80, com os estudos acerca da psicogênese da língua escrita. A primeira referência brasileira ao termo surgiu no livro No mundo da escrita: uma perspectiva psicolinguística, de autoria de Kato, em 1986, sem a definição do conceito pela autora. Posteriormente, a palavra 'letramento' apareceu, em 1988, no livro Adultos não alfabetizados - o avesso do avesso, de Tfouni, em que a autora buscou distinguir 'letramento' de 'alfabetização'. Mais adiante, o conceito foi utilizado nas publicações de Kleiman (1995), Soares (1995, 1998) e Tfouni (1995) (SOARES, 1998).

Apesar da imprecisão que ainda marca a definição de letramento na literatura educacional brasileira, Soares (2002) argumenta que, na verdade, parece não haver uma diversidade de conceitos, mas de ênfases na caracterização do fenômeno. 'Letramento', em geral, refere-se ao estado ou à condição de quem não apenas sabe ler e escrever, mas cultiva e exerce as práticas sociais que usam a escrita (SOARES, 1998). Corresponde, portanto, ao uso competente e efetivo da escrita para compreender produzir textos e viver a sociedade letrada, envolvendo a ideia de funcionalidade que ocorre em situações reais de uso da linguagem.

No Brasil, a aproximação semântica entre 'letramento' e 'alfabetização' tem 'levado à concepção equivocada de que os dois fenômenos se confundem, e até se fundem" (SOARES, 2004). Na verdade, essas práticas não devem ser confundidas, tampouco contrapostas, à medida que se integram em um mesmo processo. Nesse caso, a alfabetização corresponderia ao processo pelo qual se adquire o domínio de um código e das habilidades de utilizá-lo para ler e escrever, ou seja: o domínio da tecnologia - do conjunto de técnicas - para exercer a arte e ciência da escrita. Ao exercício efetivo e competente da tecnologia da escrita denomina-se Letramento, que implica habilidades várias, tais como: capacidade de ler ou escrever para atingir diferentes objetivos (SOARES, 2003, p. 91).

A alfabetização vincula-se ao domínio básico do código da língua, abrangendo conhecimentos e destrezas variados, como a memorização das convenções existentes entre letras/sons, a comparação entre palavras e significados, o conhecimento do funcionamento do alfabeto, o domínio do traçado das letras e a aprendizagem de instrumentos específicos, como lápis, canetas, papéis, cadernos e computador. O letramento, por sua vez, envolve o conceito de alfabetização, transcendendo a decodificação para situações em que há o uso efetivo da língua nas práticas de interação em um contexto específico. Por exemplo, o indivíduo lê um romance, executa uma receita, compreende a bula do medicamento. Pelo fato de a alfabetização e o letramento envolverem desde a decodificação de uma palavra até a leitura de uma obra, em um longo continuum, há referências a tipos e níveis de letramento, considerando, em qualquer situação, a experiência do indivíduo.

A transposição dos conceitos de alfabetização e letramento para o universo informacional pode auxiliar na construção do arcabouço conceitual do letramento informacional, visto que tratam do processo de aprendizagem. Pode-se identificar convergências entre tais conceitos, como as ideias de processo, de funcionalidade, de produção de conhecimento, dentre outras. Soares (2002), ao discutir as práticas de leitura e escrita na cibercultura, enfatiza a ideia de que "diferentes espaços de escrita e diferentes mecanismos de produção, reprodução e difusão da escrita resultam em diferentes letramentos" (2002, p. 156), reconhecendo a existência de diversos processos de letramento.

A partir dessa discussão, é necessário ater-se aos argumentos de Dudziak (2003) quando ele ressalta 
que Information Literacy transcende a simples soma dos conceitos informação e letramento, sendo um conceito essencialmente complexo e abrangente. O letramento informacional tem como finalidade a adaptação e a socialização dos indivíduos na sociedade da aprendizagem. Isso ocorre quando o sujeito desenvolve as capacidades de

- determinar a extensão das informações necessárias;

- acessar a informação de forma efetiva e eficientemente;

- avaliar criticamente a informação e a suas fontes;

- incorporar a nova informação ao conhecimento prévio;

- usar a informação de forma efetiva para atingir objetivos específicos;

- compreender os aspectos econômico, legal e social do uso da informação, bem como acessá-la e usá-la ética e legalmente.

Ao se fazer analogia entre letramento e alfabetização no contexto da informação, a alfabetização informacional, como primeira etapa do referido processo, envolve o conhecimento básico dos suportes de informação - como noção da organização de dicionários e enciclopédias -; compreensão de conceitos relacionados às práticas de busca e uso de informação, tais como números de chamada, classificação, índice, sumário, autoria, banco de dados, bem como o domínio das funções básicas do computador - uso do teclado, habilidade motora para usar o mouse, dentre outros. Por abranger os contatos iniciais com as ferramentas, produtos e serviços informacionais, a alfabetização informacional requer o desenvolvimento dessas competências desde a educação infantil.

Nesse continuum, o letramento infomacional relaciona-se à capacidade de buscar e usar a informação eficazmente, por exemplo, identificando palavras sinônimas em um dicionário, produzindo um artigo para submissão em congresso, comprando algo a partir da interpretação e sistematização de ideias ou ainda obtendo informações atualizadas e apropriadas sobre determinada doença. Assim, pode-se afirmar que a essência do letramento informacional consiste, grosso modo, no engajamento do sujeito nesse processo de aprendizagem a fim de desenvolver competências e habilidades necessárias à busca e ao uso da informação de modo eficiente e eficaz.

\section{Competências e habilidades informacionais}

O conceito de competência ${ }^{2}$ surgiu do campo empresarial e financeiro com o objetivo de buscar, por meio de programas de 'capacitação dos recursos humanos', 'reengenharia' ou 'qualidade total', alternativas para melhorar a produtividade e a competitividade em decorrência especialmente do processo de substituição tecnológica que produz novas formas de organização do trabalho (GASQUE, 2003).

No âmbito educativo, a ideia de transposição dos conteúdos do 'mundo do trabalho' para o currículo educacional situa-se no cerne do conceito de competência com a intenção de superar a lacuna existente entre os conhecimentos propiciados pela escola e aqueles requeridos pelo mercado. Assim, a noção subjacente ao conceito de competência é a aplicação do conhecimento.

Nas correntes pedagógicas mais tradicionais, o conteúdo das disciplinas constituía um fim em si mesmo. Muitas vezes, era apresentado aos alunos de maneira abstrata, sem conexão com o seu cotidiano. Cabia aos alunos memorizar as informações, quase sempre sem compreendê-las, e saberem a função delas na 'vida real'. Nessa perspectiva, o conteúdo é um meio para construir competências. Ou seja, o aluno deve aplicar o conhecimento para resolver um problema ou tomar decisão. No caso dos conteúdos necessários para aprender a buscar e a usar informação, mais do que conhecer a organização

\footnotetext{
${ }^{2} \mathrm{O}$ conceito de competência discutido neste artigo baseia-se, parcialmente, na dissertação defendida na Universidade de Brasília por Gasque em 2003.
} 
do material de referência, as normas da ABNT ou os mecanismos de buscas da internet, os indivíduos precisam, por exemplo, saber produzir um bom texto acadêmico, elaborar projetos e implementálos, comparar dados para fazer bons investimentos.

O termo competência é polissêmico. No uso informal, possui o sentido de soma de conhecimentos ou de habilidades. E, por derivação, refere-se à autoridade de um sujeito em determinado ramo do saber ou do fazer. Em outras palavras, evidencia a capacidade dos indivíduos de resolverem em problemas e realizar em tarefas específicas e circunscritas (HOUAISS, 199-?).

De acordo com o documento do Exame Nacional do Ensino Médio (Enem), do Ministério da Educação (MEC), "competências são as modalidades estruturais da inteligência, ou melhor, ações e operações que utilizamos para estabelecer relações com e entre objetos, situações, fenômenos e pessoas que desejamos conhecer". Na proposta do MEC, há vinculação estreita com o sentido de inteligência prática, em que a ação é norteada pela razão, mediando as interações que porventura possam ocorrer.

As habilidades decorrem das competências adquiridas e referem-se ao plano imediato do "saber fazer". Por meio das ações e operações, as habilidades aperfeiçoam-se e articulam-se, possibilitando nova reorganização das competências. Se a competência a ser desenvolvida vincula-se ao acesso efetivo e eficiente da informação, as habilidades prováveis seriam, por exemplo, selecionar os métodos mais apropriados de pesquisas ou sistemas de recuperação para acessar a informação necessária, planejar estratégias de busca de informação, recuperar dados em sistemas de informação. Há, portanto, uma relação de subordinação entre habilidades e competências. Porém, essa relação não é linear, tampouco rígida.

Perrenoud (2000) não diferencia competências de habilidades e de capacidades, utilizando-as como sinônimos. Para o autor, competência designa a capacidade de mobilizar diversos recursos cognitivos para enfrentar situações. Essa definição se fundamenta nos seguintes aspectos:

1) As competências não são elas mesmas saberes, savoirfaire ou atitudes, mas mobilizam, integram e orquestram tais recursos.

2) Essa mobilização só é pertinente em situação, sendo cada situação singular, mesmo que se possa tratá-la em analogia com outras, já encontradas.

3) O exercício da competência passa por operações mentais complexas subentendidas por esquemas de pensamentos (ALTET, 1996; PERRENOUD, 19961,1998g), que permitem determinar (mais ou menos consciente e rapidamente) e realizar (de modo mais ou menos eficaz) uma ação relativamente adaptada `a situação.

4) As competências profissionais constroem-se em formação, mas também ao sabor da navegação diária de um professor, de uma situação de trabalho à outra (LE BOTERF, 1997)

Esse conceito, às vezes criticado como uma perspectiva puramente técnica em contraposição à perspectiva acadêmica, tem sido incluído nas discussões dos professores e estudiosos da área educacional (GASQUE, 2003). Ramos (2002) constata grande proximidade entre as pedagogias das competências e dos objetivos com os princípios 'tayloristas' de organização do trabalho. A autora considera, entretanto, que isso contradiz as mudanças tecnológicas e organizacionais do trabalho com tendências à complexidade e à flexibilização. Ressalta que o trabalho por competências pode chegar ao condutivismo/behaviorismo ${ }^{3}$, se as competências forem reduzidas aos desempenhos observáveis e a natureza do conhecimento ao desempenho que ele pode desencadear. Isso pode ocorrer se a atividade for considerada mera justaposição de comportamentos elementares, em que a aquisição de competências corresponderia ao processo cumulativo, bem como se os processos de aprendizagem subjacentes aos comportamentos e

\footnotetext{
"Termo geral para abordagens de teorias da aprendizagem preocupadas principalmente com elementos observáveis do comportamento (como estímulos e respostas)" (LEFRANÇOIS, 2008, p. 426)
} 
desempenhos - os conteúdos da capacidade - não forem efetivamente focalizados.

Ao pensar em capacidade individual, Perrenoud (2001) argumenta que cabe ao sujeito o papel de determinar, conscientemente ou não, as relações com a situação de acordo com os seus projetos profissionais pessoais, e os próprios interesses. Contudo, isso não conduz a uma tipologia de situações próprias de cada sujeito, visto que a cultura de uma comunidade lhe fornece categorias para estruturação das representações. Ao utilizar mecanismos cognitivos semelhantes em face das mesmas situações, a tendência é gerar categorias similares. Isso significa que 'ser competente' não se traduz em 'ser original ou criativo'. Além disso, a forma como cada sujeito vincula as situações para construir uma categorização consistiria, em última instância, no campo de aplicação de suas competências.

Perrenoud (2001) ressalta que a competência pode designar uma capacidade de mobilização imediata ou mais reflexiva, dependendo da situação. Há sempre uma mobilização de conhecimento que ajuda o sujeito a agir em determinada situação, mas que provavelmente ocorre de formas muito diferentes. Se há exigência de uma ação imediata, provavelmente o sujeito se amparará nos conhecimentos disponíveis na memória naquela ocasião. Mas para que o saber oriente a ação, é necessário que haja tempo para que o indivíduo possa raciocinar, relacionar e organizar informações.

Outro ponto relevante discutido por Perrenoud (2001) diz respeito à falta de garantia de que as ações logicamente ordenadas sob o mesmo vocábulo mobilizem os mesmos recursos cognitivos. Pode-se concluir a partir desse argumento que, no processo de aprendizagem, muitas vezes, o desenvolvimento de competências pode extrapolar o que foi planejado didaticamente e mobilizar competências, habilidades e atitudes que não foram mapeadas anteriormente ao processo. Isso porque não se pode controlar todos os eventos, elementos e recursos cognitivos presentes na aprendizagem.
$\mathrm{Na}$ literatura da ciência da informação no Brasil, 'competência' é frequentemente empregada como sinônimo de letramento informacional. Todavia, competência refere-se àquilo que se deseja construir e desenvolver ao longo de um processo, no caso o de letramento informacional. Assim, propõe-se que competência seja utilizada como expressão do 'saberfazer', derivada das relações entre o conhecimento que o sujeito detém, a experiência adquirida pela prática e a reflexão sobre a ação (GASQUE, 2003). Por sua vez, habilidade é a realização de cada ação específica e necessária para alcançar determinada competência.

\section{POR UM ARCABOUÇO CONCEITUAL DE LETRAMENTO INFORMACIONAL}

O presente estudo emerge da análise de vários termos utilizados para representar o conceito de letramento informacional. Possui, pois, caráter terminológico por se relacionar aos estudos que objetivam identificar e delimitar os conceitos próprios de uma arte, ciência, profissão mediante a designação de cada um deles por determinado vocábulo (HOUAISS, 199-?).

A discussão terminológica é importante para se pensar em um arcabouço conceitual para o letramento informacional. Arcabouço carrega o sentido daquilo que precisa ser estruturado, mas também de esboço, ou seja, ação ainda incipiente no que diz respeito à construção dos conceitos. Assim, foram investigados, principalmente, na literatura da área educacional, os fundamentos teóricos com o objetivo de definir melhor os conceitos do processo supracitado. Convém destacar que a definição de cada conceito é flexível, podendo ser discutida e ampliada. Contudo, propõe-se uma primeira aproximação do arcabouço conceitual do letramento informacional com ênfase na aprendizagem (concepção da inteligência), em que se apresenta o processo e os conceitos que o integram.

Ao falar de aprendizagem, considera-se a existência de modos diferenciados de ensino-aprendizagem. 
Com a análise das práticas pedagógicas, é possível verificar o desenvolvimento de correntes de pensamento em psicologia, mais ou menos sistemáticas. Cada uma dessas correntes remete, explicitamente ou não, a uma teoria da aprendizagem. Em contrapartida, as teorias de aprendizagem remetem a determinadas práticas escolares, como o modo de elaborar o currículo, a seleção de material ou a maneira de se comunicar com os estudantes (BIGGE, 1977).

Reconhecendo que as classificações são arbitrárias e muitas vezes reducionistas, fragmentadas e simplificadas, compreende-as como necessárias para a organização do pensamento (LIBANEO, 20..?). As teorias da aprendizagem podem ser classificadas, de modo geral, em três grandes categorias: comportamentalista, cognitivista e humanista. A abordagem comportamentalista ou behaviorista percebe o indivíduo como um conjunto de respostas a um estímulo. A cognitivista ocupa-se dos processos cognitivos básicos. Por sua vez, o humanismo considera o indivíduo um ser consciente, autoorientado e criativo, possuidor do livre-arbítrio. Como os limites entre essas abordagens nem sempre podem ser claramente delimitados, em especial no que concerne ao cognitivismo e ao humanismo, há quem argumente que o "cognitivismo é um humanismo" (CASTAÑON, 2007, p.63).

Dudziak (2003), ao analisar as diferentes concepções de letramento informacional, considerando a classificação proposta por Bruce ${ }^{4}$ (1997), sugere três categorias diferenciadas pela ênfase na tecnologia da informação (concepção da informação), ênfase nos processos cognitivos (concepção cognitiva) e ênfase no aprendizado (concepção da inteligência). Essas categorias mantêm semelhanças com as abordagens psicológicas da aprendizagem. Nesse estudo, priorizam-se as ênfases nos processos cognitivos e no aprendizado.

\footnotetext{
${ }^{4}$ Bruce (1997) distingue sete concepções de letramento informacional: a da tecnologia da informação, das fontes de informação, do processo de informação, controle da informação, construção do conhecimento, extensão do conhecimento e, por fim, a concepção de inteligência.
}

A concepção cognitiva centra-se no indivíduo e nos processos de compreensão e uso da informação em situações particulares. Procura-se entender como as pessoas buscam sentido para seus questionamentos e dúvidas. O ensino relaciona-se com a motivação. A ênfase no aprendizado centra-se na construção de redes semânticas necessárias à compreensão de mundo e na construção de conhecimentos, competências e valores relacionados à dimensão social e situacional, sustentando-se no conceito de inteligência, que se relaciona à capacidade pessoal de adaptação ao meio ambiente. O ensino centra-se na ação do indivíduo sobre o conhecimento. Essas abordagens possuem características convergentes. A concepção da inteligência não exclui a ênfase cognitiva, pelo contrário, são complementares. Neste estudo, ao considerar a ênfase na aprendizagem, não se exclui a concepção cognitiva. Isso porque o conhecimento é construído na interação entre o indivíduo e o mundo físico e real por meio da estrutura cognitiva, em que a reflexão se constitui como elemento crucial.

A partir da revisão de literatura, adota-se a ideia de que o letramento informacional é um processo de aprendizagem, compreendido como ação contínua e prolongada, que ocorre ao longo da vida. O sentido da aprendizagem relaciona-se à construção do conhecimento, inerente ao ser humano, que perpassa as várias atividades do comportamento informacional. Segundo Dewey (1979), aprendizagem relaciona-se ao aprender a pensar, considerando as experiências e informações, que abrangem as atitudes, as disposições morais e o cultivo das apreciações estéticas. Assim, entendese tal processo como o conjunto das mudanças relativamente permanentes resultantes das relações entre a nova informação, a reflexão e a experiência prévia, sem desconsiderar as interações do indivíduo com o meio social.

Não há como discutir letramento informacional e os conceitos relacionados sem se referir ao processo de aprendizagem, que pode ocorrer de maneira informal ou formal. No primeiro caso, o indivíduo aprende por observação, tentativa e erro ou com 
ajuda pontual de alguém que detém a experiência. No segundo, diz-se que é formal, quando sistematizado pelas instituições de ensino. Nesse caso, reconhecese que, no Brasil, o processo de letramento informacional não tem sido foco da educação, em especial da educação básica. Na graduação, com a exigência dos trabalhos de conclusão de curso (TCCs), os alunos têm a possibilidade de desenvolver atitudes científicas, adquirindo as competências mínimas para produzir conhecimento científico. Contudo, são constatadas graves deficiências para que o projeto seja levado a efeito, principalmente quando se considera o desempenho médio dos estudantes de graduação. Os problemas, de maneira geral, estão vinculados a (1) à dificuldade em mudar a cultura pedagógica; (2) à formação inadequada dos professores; (3) à concepção de ensinoaprendizagem, (4) à organização do currículo e (5) à ausência de infraestrutura adequada de informação (GASQUE, TESCAROLO, 2010). Assim, a proposta de letramento como um continum deve ser sistematizada desde a educação infantil.

A primeira etapa do letramento informacional, denominada alfabetização informacional, refere-se à compreensão básica do código, no caso, os conceitos relacionados à informação e aos seus suportes, bem como as noções da organização desses serviços e produtos. Concomitantemente, na segunda etapa, delimitada apenas para fins didáticos, a alfabetização deve ocorrer com vista à aplicação prática desse conhecimento, o letramento propriamente dito, que se refere à capacidade de selecionar, buscar e avaliar as informações, organizá-las e usá-las eticamente para produzir novos conhecimentos. Ou seja, ao longo desse processo, os indivíduos precisarão desenvolver competências e habilidades para lidar com o universo informacional. Tais conceitos estão inter-relacionados hierarquicamente e correspondem ao desempenho final a ser obtido. Cada habilidade realizada representa uma fase ou passo em direção ao desenvolvimento da competência, reconhecendo que as competências podem ser adquiridas em níveis diferenciados de acordo com a experiência do sujeito, bem como com a forma de planejamento do ensino-aprendizagem.

\section{CONCLUSÃO}

A discussão terminológica é importante contribuição epistemológica para a consolidação do arcabouço conceitual do 'letramento informacional', cujos estudos se intensificaram no Brasil no início deste século, confirmando a necessidade de amadurecimento dos conceitos envolvidos no processo. O referido arcabouço, em fase de reestruturação e maturação, apresenta ainda a natureza incipiente de esboço no que concerne à construção dos conceitos. Desse modo, ressalta-se a necessidade de mais debates e pesquisas sobre o tema, considerando vários pontos de vista para a consolidação desse arcabouço.

O letramento constitui-se no processo de aprendizagem necessário ao desenvolvimento de competências e habilidades especificas para buscar e usar a informação. Há fortes evidências de que tal processo é crucial na sociedade atual, submetida a rápidas e profundas transformações devido à grande produção de conhecimentos científicos e tecnológicos. Reconhece-se, de acordo com Herbert Simon (2000), prêmio Nobel de Economia em 1978, que o significado do saber mudou, sendo hoje muito mais importante buscar e usar informações do que memorizá-las. No contexto contemporâneo, o indivíduo precisa ser "informacionalmente" letrado para atuar como cidadão crítico e reflexivo, dotado de autonomia e responsabilidade e, desse modo, colaborar na superação dos graves problemas de toda ordem que atingem hoje a humanidade.

Diante disso, impõe-se discutir sistemicamente as ações políticas, culturais, educacionais, socioambientais e econômicas dos vários segmentos da sociedade capazes de efetivamente contribuir para a consolidação desse processo, de forma concreta e sistematizada, em todos os níveis de ensino. Isso porque o letramento informacional possibilita, mais do que a aquisição de conteúdos e competências, a sabedoria do aprender a aprender, contribuindo para a sustentabilidade da vida e a solidariedade humana na sociedade contemporânea. 
Arcabouço conceitual do letramento informacional

\section{Agradecimentos}

Aos professores doutor Ricardo Tescarolo e doutora Isabel Cristina Michelan de Azevedo, pela disponibilidade e contribuições valiosas ao trabalho.

Artigo submetido em 10/09/2010 e aceito em 13/07/2011.

\section{REFERÊNCIAS}

ALTET, M. Les compétences de l'enseignant-professionnel: entre savoirs, schèmes d'action et adaptation, le savoir analyser. In: L. Paquay et al (Eds.). Former des enseignants professionnels. Quelles stratégies? Quelles compétences? Bruxelles: De Boeck, 1996. p. 27-40.

ASSOCIATION OF COLLEGE AND RESEARCH LIBRARY. Information literacy competency standarts for higher education. Chicago: ALA, 2000

BRASIL. Ministério da Educação. Instituto Nacional de Estudos e Pesquisas Educacionais. Exame Nacional do Ensino Médio. Documento básico. Disponível em: <http//www.inep.gov.br/>. Acesso em: 21 set. 2001.

BIGGE, Morris L. Teorias da aprendizagem para professores. São Paulo: EPU 1977.

BELluZZO, Regina Célia Baptista. Competências na era digital: desafios tangíveis para bibliotecários e educadores. ETD - Educação Temática Digital, v. 6, n. 2, p. 27-42, 2005.

BREIVIK, P. S. Putting libraries back in the information society. American Libraries, v.16, n.1, 1985.

BRUCE, C. S. Seven faces of information literacy. Adelaide: Aslib, 1997

CALDAS AULETE dicionário on-line. Disponível em:<www. auletedigital.com.br>. Acesso em: 20 mar. 2010.

CAMPELLO, Bernadete. Letramento Informacional - Função Educativa do Bibliotecário na Escola. Belo Horizonte: Autêntica, 2009.

O movimento da competência informacional: uma perspectiva para o letramento informacional. Ciência da Informação, v.32, n.3 Brasília, Set./Dez. 2003. Disponível em: < http://www.scielo. br/scielo.php?script=sci_arttext\&pid=S0100-19652003000300004>. Acesso em: 28 mai. 2009.

- A competência informacional na educação para o século XXI. In: Campello, B.; CALDEIRA, P. (orgs). Biblioteca escolar temas para uma prática pedagógica. Belo Horizonte: Autêntica, 2002. p. 9-11.

CASTAÑON, Gustavo Arja. O Cognitivismo é um Humanismo. Psicologia Argumentativa, Curitiba, v. 25, n. 48 p. 51-64, jan./mar. 2007. Disponível em: <www2.pucpr.br/reol/index.php/PA?dd99=view...> Acesso em: 01 jun. 2011.

DEWEY, John. Como pensamos: como se relaciona o pensamento reflexivo com o processo educativo, uma reexposição. 4.ed. São Paulo: Nacional, 1979.
DUDZIAK, Elisabeth Adriana. Competência informacional: análise das tendências da pesquisa e produtividade científica em âmbito mundial. Inf. Inf., Londrina, v. 15, n. 2, p. 1 - 22, jul./dez. 2010. Disponível em: <www.uel.br/revistas/uel/index.php/informacao/ article/download/.../6994>. Acesso em: 31 mai. 2011.

. Information literacy: princípios, filosofia e prática. Ciência da Informação, Brasília, v. 32, n. 1, Apr. 2003. Disponível em:<http:// www.scielo.br/scielo.php?script $=$ sci_arttext\&pid $=S 0100$ 19652003000100003\&lng=en\&nrm=iso >. Acesso em: 20 jun. 2010.

FIALHO, Janaina Ferreira. o prêmio jovem cientista e o comportamento informacional do pesquisador. Enc. Bibli: R. Eletr. Bibliotecon. Ci. Inf, Florianópolis, v. 16, n. 31, p.88-109, 2011. Disponível em: < www.periodicos.ufsc.br/index.php/eb/article/ download/1518.../17763>. Acesso em: 30 mai. 2011.

A cultura informacional e a formacão do jovem pesquisador brasileiro. 2009. Tese (Doutorado em Ciência da Informação) - Escola de Ciência da Informação, Universidade Federal de Minas Gerais, Belo Horizonte. Disponível em: <http://www.bibliotecadigital.ufmg.br/dspace/ handle/1843/ECID-7VYQNZ?mode=full> . Acesso em: 30 mai. 2011.

GARFIELD, E. 2001: An Information Society? Journal of Information Science, v.1, p. 210, 1979. Disponível em: < www.garfield.library.upenn. edu/essays/v6p609y1983.pdf>. Acesso em: 30 mai. 2011.

GASQUE, Kelley Cristine Gonçalves Dias. O pensamento reflexivo na busca e no uso da informação na comunicação científica. 2008. Tese (Doutorado em Ciência da Informação) - Departamento de Ciência da Informação, Faculdade de Estudos Sociais Aplicados, Universidade de Brasilia, Brasilia.

GASQUE, Kelley Cristine Gonçalves Dias; TESCAROLO, Ricardo. Desafios para implementar o letramento informacional na educação básica. Educação em Revista, UFMG, Belo Horizonte, v. 26, n. 1, Apr. 2010. Disponível em: <http://www.scielo.br/scielo.php?pid=S010246982010000100003\&script=sci_arttext $>$. Acesso em: 01 mar. 2010.

O pensamento reflexivo na busca e no uso da informação. In: ENCONTRO NACIONAL DE PESQUISA EM CIÊNCIA DA INFORMAÇÃO, 7., 2006, Marília/SP. Anais... Marília: Unesp, 2006. p. 432-440. Disponível em: $<$ http://www.portalppgci.marilia. unesp.br/enancib/viewpaper.php?id=69> . Acesso em: 20 mar. 2010.

Comportamento dos professores da educação básica na busca de informação para formação continuada. 2003. Dissertação (Mestrado em Ciência da Informação) - Departamento de Ciência da Informação, Faculdade de Estudos Sociais Aplicados, Universidade de Brasília, Brasília.

HOUAISS. Dicionário Houaiss de Língua Portuguesa. Versão Eletrônica. Disponível em: < http://houaiss.uol.com.br>. Acesso em: 8 jul. 2009.

KATO, Mary. No mundo da escrita: uma perspectiva psicolingüística. São Paulo: Ática, 1986. (Série Fundamentos).

KLEIMAN, Ângela B. (Org.). Os significados do letramento: uma nova perspectiva sobre a prática social da escrita. Campinas: Mercado de Letras, 1995.

KUHLTHAU, Carol C. An emerging theory of library instruction. School libray media quarterly, v. 16, 1987, p. 23-28.

LE BOTERF, G. De la compétence à la navigation professionnelle. Paris: Les Éditions d'organisation, 1997. 


\section{Kelley Cristine Gonçalves Dias Gasque}

LEFRANÇOIS, Guy R. Teorias da aprendizagem. São Paulo: Cengage Learning, 2008.

LIBÂNEO, José Carlos. As teorias pedagógicas Modernas revisitadas pelo Debate Contemporâneo na Educação. (20--?). Disponível em: <http:// pt.scribd.com/doc/16367378/Teorias-Pedagogicas-modernasLibaneo>. Acesso em: 10 nov. 2010.

LINS, G. S; LEITE, F. C. L. comportamento informacional como aporte teórico para consolidação conceitual de competência informacional no contexto da comunicação científica. In: SEMINÁRIO NACIONAL DE BIBLIOTECAS UNIVERSITÁRIAS, 15., 2008, São Paulo. Anais... São Paulo, 2008. Disponível em:< www.sbu.unicamp.br/ snbu2008/anais/site/pdfs/2698.pdf>. Acesso em: 10 nov. 2009.

LISTON; Rose, SANTOS; Plácida. Representando a Information Literacy "Competências Informacionais" na Biblioteconomia. Em Questão, v. 14, n.2, 2008. Disponível em: < http://www.seer.ufrgs.br/index.php/ EmQuestao/article/viewArticle/5043/4875>. Acesso em:10 de mai. 2009.

MARZAL, M.A.; PRADO, J. Calzada. (2007). 15 años de Alfabetización en Información: investigación internacional recogida en LISA, ERIC y SSCI entre 1990 y 2005 // Boletín de la Asociación Andaluza de Bibliotecarios. 22:86-87 15-27.

MIRANDA, Silvânia Vieira. Identificando competências informacionais. Ciência da Informação, Brasília, v. 33, n. 2, p. 112-122, maio/ago. 2004. Disponível em: < www.scielo.br/pdf/ci/v33n2/ a12v33n2.pdf>. Acesso em: 10 de mai. 2010.

MODERNO DICIONÁRIO DA LÍNGUA PORTUGUESA MICHAELIS. São Paulo: Melhoramentos, C 1998-2007. Disponível em: < http://houaiss.uol.com.br/busca.jhtm?verbete=literacia\&sty $\mathrm{pe}=\mathrm{k} \& \mathrm{x}=19 \& \mathrm{y}=9>$. Acesso em: 20 nov. 2009.

NEVES, Barbara Coelho. Resenha de WARSCHAUER, Mark. Technology and social inclusion: rethinking the digital divide. Massachusetts: MIT Press, 2003. Ponto de Acesso, Salvador, v.2, n.2, p. 170-174, ago. /set. 2008. Disponível em: < www.pontodeacesso.ici. ufba.br>. Acesso em: 20 nov. 2009.

PERRENOUD, Philippe. De la réflexion dans le feu de l'action à une pratique réflexive. Université de Genève: Faculté de psychologie et des sciences de l'éducation, 1998.

. Dez novas competências para ensinar: convite à viagem. Porto Alegre: Artmed, 2000

. Ensinar: agir na urgência, decidir na incerteza - saberes e competências em uma profissão complexa. Porto Alegre: Artmed, 2001

. Le travail sur l'habitus dans la formation des enseignants. Analyse des pratiques et prise de conscience. In : L. Paquay et al (Eds.). Former des enseignants professionnels. Quelles stratégies? Quelles compétences? Bruxelles: De Boeck, 1996. p. 181-208.

RAMOS, Marise Nogueira. A educação profissional pela Pedagogia das Competências e a superfície dos documentos oficiais. Educação e Sociedade, Campinas, v. 23, n. 80, setembro/2002, p. 401-422. Disponível em:< http://www.scielo.br/pdf/es/v23n80/12939.pdf>. Acesso em: 01 jun. 2009.

SILVA, Armando Malheiro da; FERNÁNDEZ MARCIAL, Viviana; MARTINS, Fernanda (2007). A Literacia Informacional no Espaço Europeu de Ensino Superior: Fundamentos e objectivos de um projecto em várias fases. In: CONGRESSO BAD, 9., 2007, Ponta Delgada, Portugal. Anais... Ponta Delgada, 2007.

SILVA, Helena et al. Inclusão digital e educação para a competência informacional: uma questão de ética e cidadania. Ciência da Informação, Brasília, v. 34, n. 1, p.28-36, jan./abr. 2005. Disponível em:< revista. ibict.br/index.php/ciinf/article/viewPDFInterstitial/611/544>. Acesso em: 28 de mai. 2009.

SIMON, Herbert A. Observations on the Sciences of Science Learning. Journal of Applied Developmental Psychology, v. 21, n.1, 2000. p. 115-121.

SOARES, Magda. Letramento e alfabetização: as muitas facetas. Revista Brasileira de Educação, n. 25, 2004. Disponível em:< http:/ /www. scielo.br/pdf/rbedu/n25/n25a01.pdf>. Acesso em: 28 ago. 2010.

. Letramento e escolarização. In: RIBEIRO, Vera Masagão (org.). Letramento no Brasil. São Paulo: Global, 2003. p. 89-113.

Língua escrita, sociedade e cultura: relações, dimensões e perspectivas. Revista Brasileira de Educação, n. 0, 1995, p. 5-16. Disponível em: <http://www.anped.org.br/rbe/rbedigital/RBDE0/RBDE0_03_ MAGDA_BECKER_SOARES.pdf $>$. Acesso em: 20 ago. 2010

Novas práticas de leitura e escrita: letramento na cibercultura. Educação e Sociedade, Campinas, vol. 23, n. 81, p. 143-160, dez. 2002. Disponível em: http://www.cedes.unicamp.br. Acesso em: 15 jul. 2010.

. Letramento: um tema em três gêneros. Belo Horizonte: Autêntica, 1998.

STERNBERG, R. J. Psicologia cognitiva. Porto Alegre: Artmed, 2000.

TIRADO, Alejandro Uribe. La Alfabetización Informacional en Iberoamérica. Ibersid. (2010). Disponível em: <eprints.rclis.org/ bitstream/.../IBERSID-AlfinIberoamérica.UribeTirado,A.pdf $>$. Acesso em: 31 mai 2011.

TAYLOR, R. S. Reminiscing about the future. Library Journal, v.104, p. 1895-1901, sept. 1979.

TFOUNI, Leda Verdiani. Adultos não alfabetizados: o avesso do avesso. Campinas: Pontes, 1988.

TFOUNI, Leda Verdiani. Alfabetização e letramento. São Paulo: Cortez, 1995. (Coleção Questões de nossa época).

VITORINO, Elizete Vieira; PIANTOLA, Daniela. Competência informacional - bases históricas e conceituais: construindo significados. Ciência da Informação, Brasília, v. 38, n. 3, p.130-141, set./dez., 2009. Disponível em: < revista.ibict.br/index.php/ciinf/ article/.../1745>. Acesso em: 31 mai. 2011.

VITORINO, E. V. Competência informacional: princípios para a formação contínua de profissionais da informação em bibliotecas universitárias. In: SEMINÁRIO NACIONAL DE BIBLIOTECAS UNIVERSITÁRIAS, 15., São Paulo. Anais... São Paulo, 2008. Disponível em:< www.sbu.unicamp.br/snbu2008/anais/site/ pdfs/2698.pdf>. Acesso em: 10 nov. 2009.

ZURKOWSKI, P. G. Information services environment relationships and priorities. Washington D.C.: National Commission on Libraries, 1974. Disponível em: < http://www.eric.ed.gov/PDFS/ED100391.pdf>. Acesso em: 2 mar. 2010. 